\title{
THE DEVELOPMENT OF REGRYSTALLIZATION TEXTURES IN F.C.C. METALS WITH A LOW STACKING FAULT ENERGY*†
}

\author{
J. W. H. G. SLAKHORST +
}

The texture development of silver single crystals and polycrystalline high purity silver and a series of $\mathrm{Ni}$-Co alloys was examined, immediately after rolling and after various annealing treatments. $\mathrm{X}$-ray diffraction and electron-microscopical observations showed that the development of the $\{841\}\langle 447\rangle+$ $\{310\} 001\rangle+\{852 i\}\langle 245\rangle$ recrystallisation texture can be explained by the inverse Rowland transformation as the primary nucliation mechanism followed by recrystallisation twinning and growth selection of secondery twins.

DEVELOPPEMENT DE TEXTURES DE RECRISTALLISATION DANS LES METAUX C.F.C. A BASSE ENERGIE DE DEFAUT D'EMPILEMENT

Le développement de la texture de monocristaux d'argent, de polyeristaux d'argent de haute pureté et d'une série d'alliages $\mathrm{Ni}$-Co a été étudié, immédiatement après laminage et après divers recuits. La diffraction de rayons-X et les observations au mieroscope électronique ont montré que l'on pouvait expliquer le développement de la texture de recristallisation $\{841\} 4447\rangle+\{310\}\langle 001\rangle+\{852\}\langle 245\rangle$ par la transformation de Rowland inverse comme mécanisme de germination primaire suivi d'un maclage de recristallisation et d'une croissance sélective de macles secondaires.

DIE ENTWICKLUNG EINER REKRISTALLISATIONSTEXTUR IN F.C.C. METALLEN MIT NIEDRIGER STAPELFEHLERENERGIE

Die Entstehung der Textur in Silberenikristallen, in polykristallinem, hochreinem Silber und in einer Reihe von $\mathrm{Ni}$-Co-Legierungen wurde unmittelbar nach dem Walzen und nach verschiedenen Anlaßbehandlungen untersucht. Röntgenbeugung und elektronenmikroskopische Bobachtungen zeigen, daß man die Ausbildung der $\{841\}\langle 447\rangle+\{310\}\langle 001\rangle+\{852 i\}\langle 245\rangle$ Rekristallisationstextur so erklären kann, daß auf die Rowland-Umwandlung als primärer Keimbildungsmechanismus eine Rekristallisations. Zwillingsbildung und Wachstumsselektion sekundärer Zwillinge erfolgt.

\section{INTRODUCTION}

The apparent success of the theory of oriented growth $^{(1-3)}$ in explaining a variety of observed annealing textures has for some time diminished the interest in the older theories of oriented nucleation. ${ }^{(4-6)}$ There is little doubt about the fact that the orientation relationship between recrystallisation texture and deformation texture is determined exclusively by the rules of growth selection if nuclei in all possible orientations are present. ${ }^{(7.8)}$ It is however not conceivable that this condition is met in most of the deformation structures. A hard nut to crack for the theory of oriented growth has always been the cube texture in f.c.c. metals and alloys with a relatively high stacking fault energy, such as $\mathrm{Al}, \mathrm{Ni}, \mathrm{Cu} \mathrm{Au}$ and $\alpha \mathrm{Fe}-\mathrm{Ni}$. More recent observations by Horiuchi et $a l$. (9) $^{(9)}$ inkel et al..$^{(19)}$ and Ray et al..$^{(11)}$ seem to confirm the old theory of oriented nucleation proposed by Burgers and Verbraak ${ }^{(12-14)}$ which explains the cube texture by an inverse Rowland transformation of the main components of the deformation texture. With respect to f.c.c. metals and alloys with a low stacking fault energy such as $\mathrm{Ag}$ and $\alpha$-brass the theory of

* Received May 17, 1974.

+ This work is part of the research programme of the re. search group FOM-TNO of the "Stichting voor fundarnenteel onderzoek der materie" (Foundation for fundamental research of matter-F.O.M.) and was made possible by financial support from the "Nederlandse organisatie voor zuiver wetenschappelijk onderzoek" (Dutch organisation for pure researchZ.W.O.).

$\ddagger$ Mechanical Department Materials Section, Technical University Twente Enschede, The Netherlands.

ACTA METALLURGICA, VOL, 23, MARCH 1975 oriented growth seemed to provide a reasonable explanation of the observed annealing textures. The experimental fact, however, that in some cases only a part of the orientations predicted by the theory of oriented growth are actually formed, may be an indication that even in these metals oriented nucleation cannot be altogether neglected. Besides this, even if all orientations were present usually the clockwise rotation is about a different angle from the anti-clock wise rotation. ${ }^{(15.16)}$ Recently Peters and Reid ${ }^{(17,18)}$ concluded from their experiments on bronze and austenitic steel that the formation of recrystallisation textures in f.c.c. metals with a low stacking fault energy is governed by twinning. Their results are in agreement with those of Gindraux and Form. (19) In the present paper, new results on $\mathrm{Ag}$ and $\mathrm{Ni}-\mathrm{Co}$ alloys will be presented. These results confirm the important role played by twinning in the formation of annealing textures of f.c.c. metals with a low stacking fault energy. Quite unexpectedly it was found, however, that also in these metals the inverse Rowland transformation apparently is responsible for the first recrystallised nuclei formed in the cold rolled matrix. These primary nuclei with a cube orientation and their twins limit the number of possible orientations as predicted by the theory of oriented growth.

\section{EXPERIMENTS}

The experiments were carried out mainly with polycrystalline $\mathrm{Ag}(99,999$ per cent, obtained from Johnson 
and Matthey) and an Ag single crystal randomly oriented (obtained from Metals Research). From the single crystal, small specimens with an orientation (100)[011] were cut, with a M.R. sparking machine. Both the single crystal and the polycrystalline $\mathbf{A g}$ were rolled, while being inserted in soft-annealed polycrystalline $\mathrm{Cu}$. The rolling process was carried out on a Bühler rolling mill with a roll diameter $160 \mathrm{~mm}$ at $24 \mathrm{rev} / \mathrm{min}$ per min in steps of 1 per cent of the total deformation. The final deformation was always more than 99.5 per cent. After the rolling process, the specimens were stored in liquid nitrogen. For observations in the electron microscope, part of the specimens were polished electrochemically in a solution of $67.5 \mathrm{~g} \mathrm{KCN}, 15 \mathrm{~g} \mathrm{~K}-\mathrm{Na}$ tartrate, $15 \mathrm{~g} \mathrm{~K} \mathrm{~K}_{4} \mathrm{Fe}(\mathrm{CN})_{6}$, $19.5 \mathrm{~cm}^{3} \mathrm{H}_{3} \mathrm{PO}_{4}$ and $2.5 \mathrm{~cm}^{3} \mathrm{NH}_{4} \mathrm{OH}$ in $11 \mathrm{H}_{2} \mathrm{O}$ (after Bailey and Hirsch). The recrystallisation kinetics of the polycrystalline Ag were measured by means of resistivity measurements. From these recrystallisation data specific annealing treatments could be chosen for the study of the development of the recrystallisation texture. The texture determinations were carried out on a on a Philips texture goniometer with a pitch of $5^{\circ}$. The angle from the rolling plane (i.e. the plane of the stereographic projection) was restricted to $80^{\circ}$. Besides this, a number of specimens have been studied in the electron microscope (Philips E.M. 300).

\section{RESULTS}

\section{(a) The as rolled specimens}

Both in the rolled polycrystalline Ag as in the rolled Ag single crystal, the deformed material had a very sharp (011)[211] $+(011)[\overline{21} 1]$ texture. However, a large number of microtwins are observed as shown in Fig. 1. In the (011)[211] component most of the twins were formed on the (111) plane and in the (011)[211] component on the (III) plane. So, most of the twins were formed on the $\{111\}$ plane perpendicular to the rolling plane and parallel to the rolling direction. Some twins, however, were observed on the (III) and (II1) planes respectively, which results in the orientations (011)[255] and (011)[255] (compare Fig. 11).

None of these twins are oriented favorably for deformation (the resolved shear stress for twinning on these planes is zero). Because of this, these twins have to be attributed to recrystallisation during rolling. This is also confirmed by the fact that they are nucleated at the grain boundaries, and have very sharp and straight boundaries. From these observations it may be concluded that during the rolling process, twinning occurs due to recrystallisation.

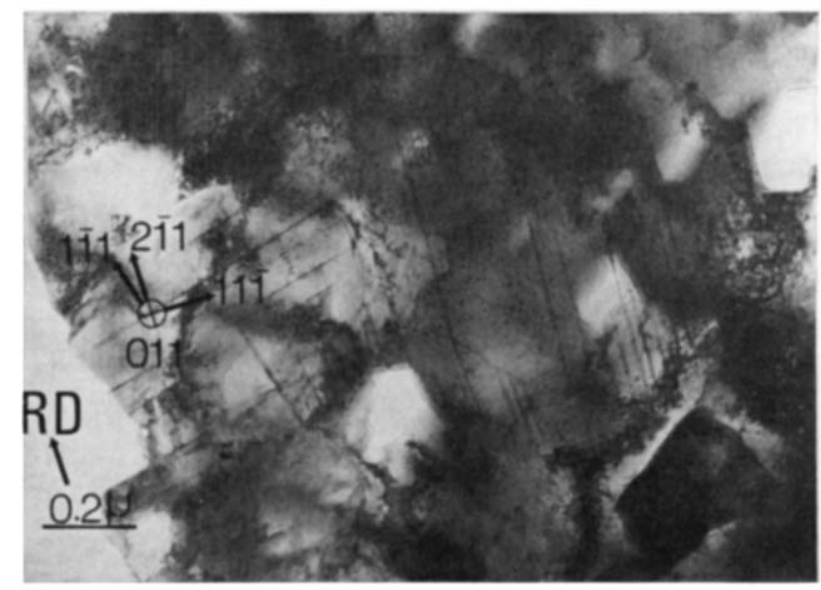

Fra. 1(a). Micro twins produced on the (111) planes perpendicular to the rolling planes in polycristalline $\mathrm{Ag}$ $(5 N)$ rolled 99.5 per cent; immediately after rolling.

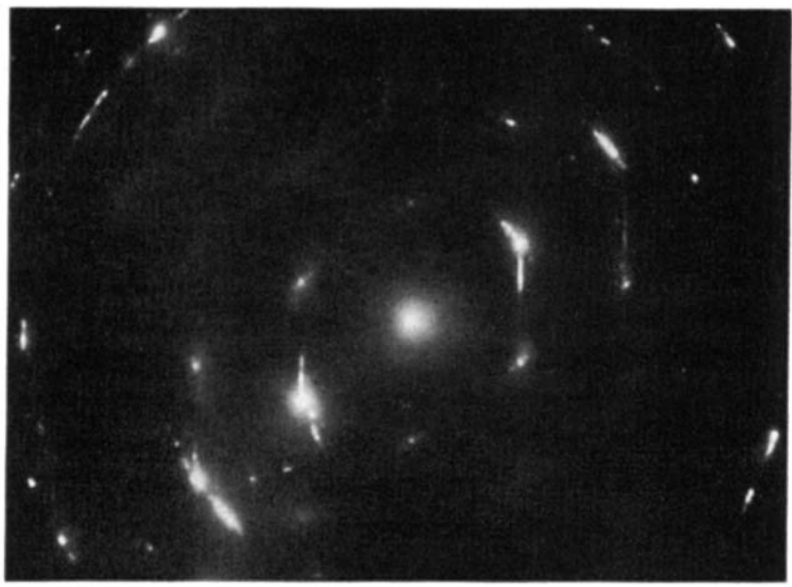

FIa. 1(b). Diffraction pattern of Fig. 1(a).

\section{(b) Recrystallisation kinetics}

For the study of the development of recrystallisation textures, it is necessary to know the degree of recrystallisation as a function of both time and temperature. These functions are given in the curves of Fig. 2. From these curves, a number of heat treatments were chosen to be examined by $\mathrm{X}$-ray diffraction and the electron microscope. These specimens are indicated in Fig. 2.

\section{(c) Texture development}

1. Measurements with the texture goniometer. The specimens, heat treated at $100^{\circ} \mathrm{C}$ and $140^{\circ} \mathrm{C}$ have been studied most extensively. From these texture measurements it may be concluded that the texture development due to recrystallisation is as follows:

The first change of the texture due to recrystallisation is the development of a texture component which 


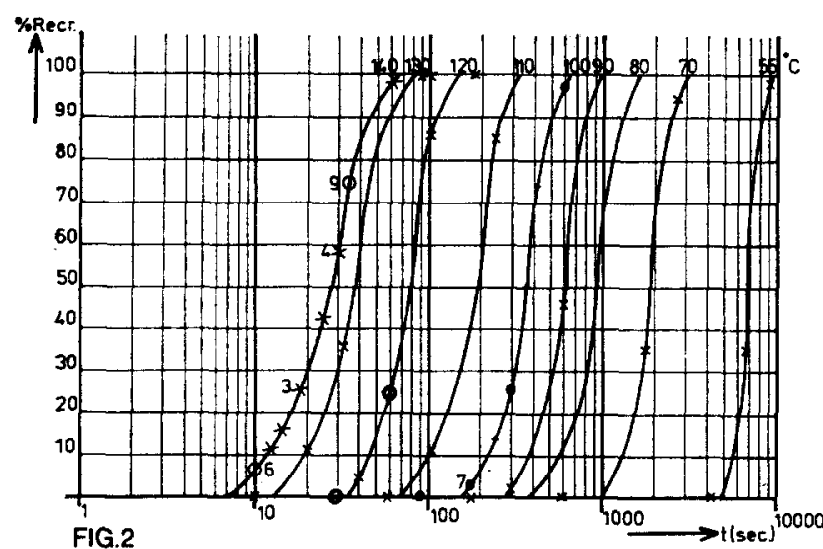

Fig. 2. Recrystallisation curves of polycrystalline Ag $(5 N)$ rolled 99.5 per cent; calculated from - resistivity measurements. Those treatments, from which pole figures are messured, are marked by crosees of which the numbers correspond to those of the pole figures and the treatments which are studied in the electron microscope are marked with small circles with the corresponding figure numbers.

can be described as $\{852\}\langle 452\rangle$ of which the permuta tions $(\overline{258})[45 \overline{2}],(\overline{2} 85)[4 \overline{2} 5],(258)[\overline{4} 5 \overline{2}]$ and $(285)[\overline{425}]$ are observed. Also a considerably weaker $\{310\}\langle 001\rangle$ texture component has developed (permutations $(013)[100]+(031)[100])$. This is shown in Fig. 3 for a specimen heat treated $18 \mathrm{sec}$ at $140^{\circ} \mathrm{C}$. At this stage of recrystallisation, however, the strongest texture component is still the deformation twin texture (011)[211] $+(011)[\overline{2} 11]$. Furthermore in this stage another new component has developed which can be described as \{841\}[474]. (Permutations which are present (148) $[\overline{4} 7 \overline{4}],(\overline{184})[\overline{4} 7] ;(148)[47 \overline{4}]$ and $(184)[4 \overline{4} 7]$.) After an anneal of $30 \mathrm{sec}$ at $140^{\circ} \mathrm{C}$ (Fig. $4 \mathrm{a}, \mathrm{b}$ ), by far the strongest texture component is the $\{852\}\langle 452\rangle$ texture. By now, the deformation texture seems to have vanished and the $\{031\}\langle 100\rangle$ and $\{841\}\langle 474\rangle$ components have increased in strength. This tendency is observed throughout the recrystallisation process, but further pole figures have been omitted for the cause of brevity.

Although it is not easy to distinguish between the maxima of the various texture components, a plot of the highest maximum of a certain texture component, as a percentage of the sum of all the highest maxima gives a fairly good impression of the texture development due to recrystallisation (Fig. 5). This method was proposed by F. Haessner ${ }^{(20)}$ for the $\mathrm{Cu}$ to $\mathrm{Ag}$ type rolling texture development in a series of $\mathrm{Ni}-\mathrm{Co}$ alloys. Although this method is used here for a much more complicated case, it seems to provide fair results.

2. Observations with the electron microscope. The beginning of recrystallisation was observed after

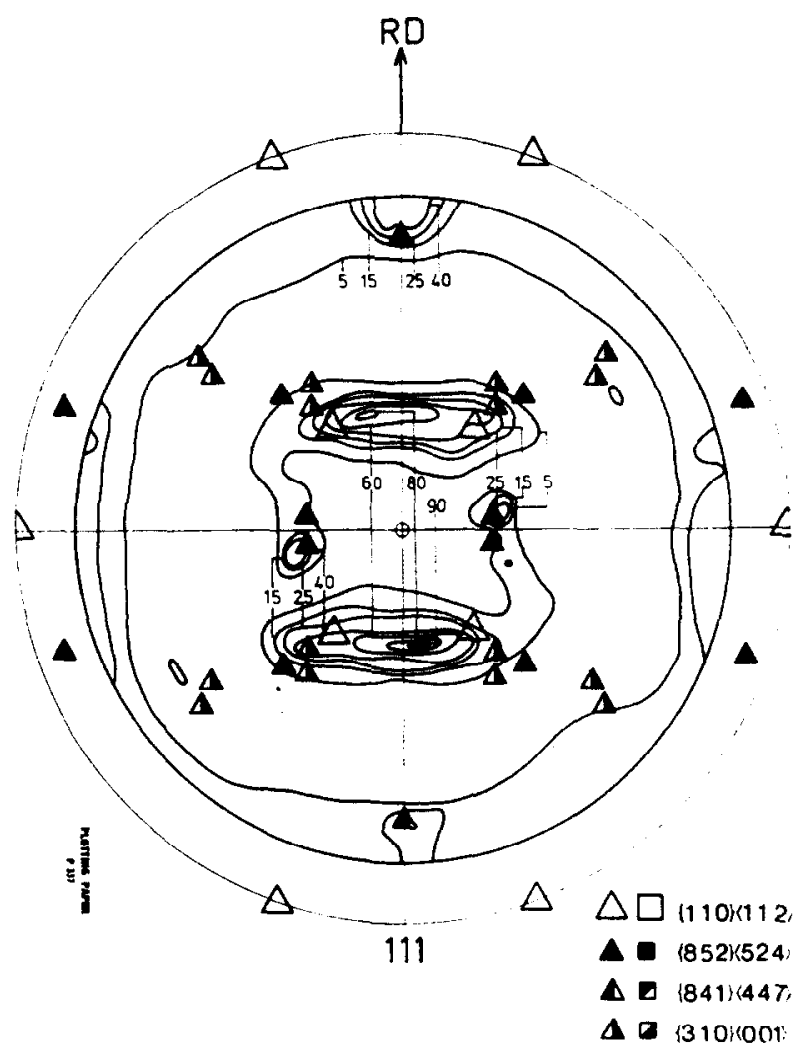

Fia. 3(a). $\{111\}$ pole figure of $\mathrm{Ag}$ specimen, rolled 99.5 per cent annealed $18 \mathrm{sec}$ at $140^{\circ} \mathrm{C}$.

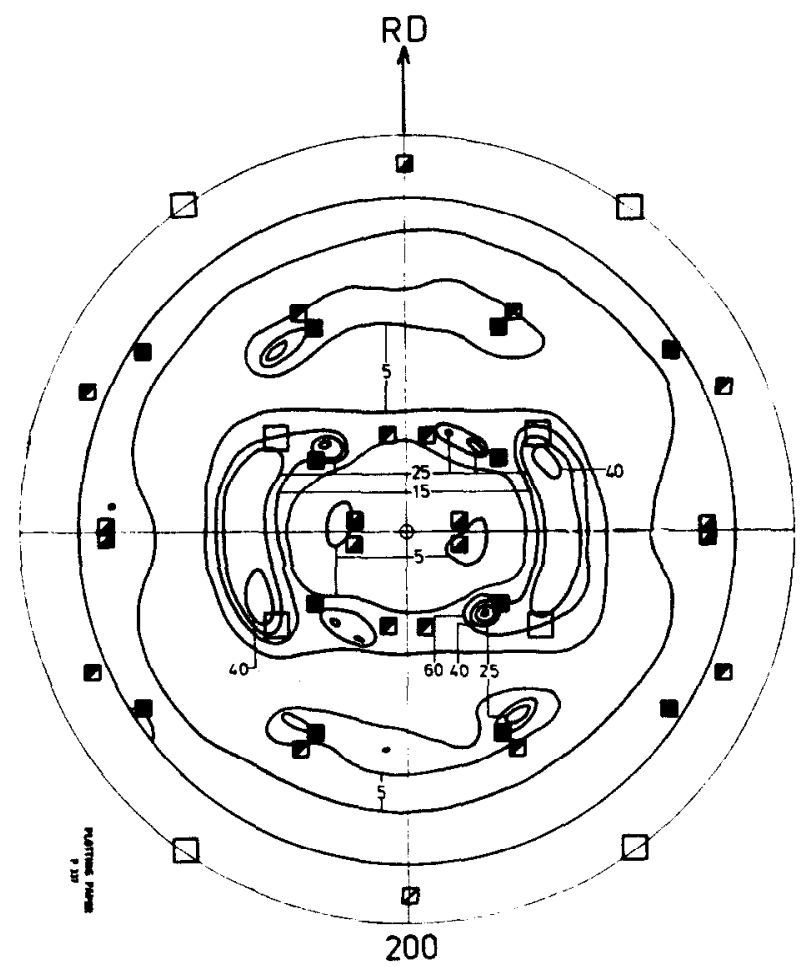

Fia. 3(b). $\{200\}$ pole figure of $\mathrm{Ag}$ specimen. rolled 99.5 per cent annealed $18 \mathrm{sec}$ at $140^{\circ} \mathrm{C}$. 


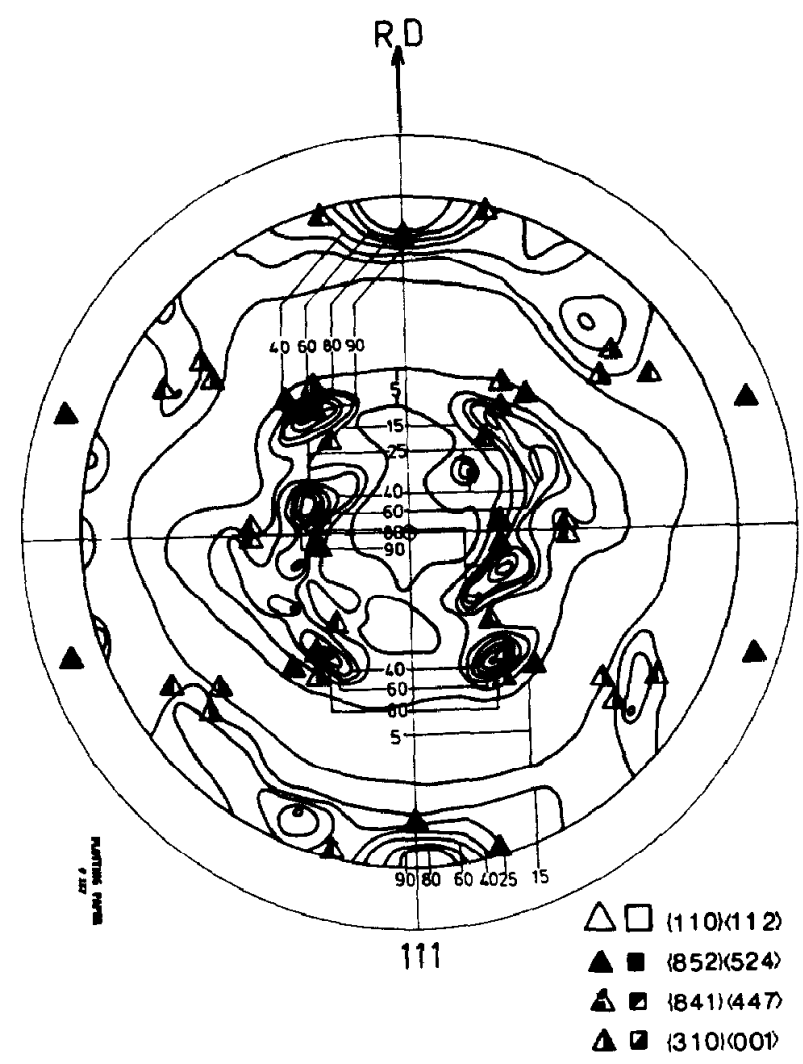

FIG. 4(a). \{111\} pole figure of $\mathrm{Ag}$ specimen, rolled 99.5 per cent annealed $30 \mathrm{sec}$ at $140^{\circ} \mathrm{C}$.

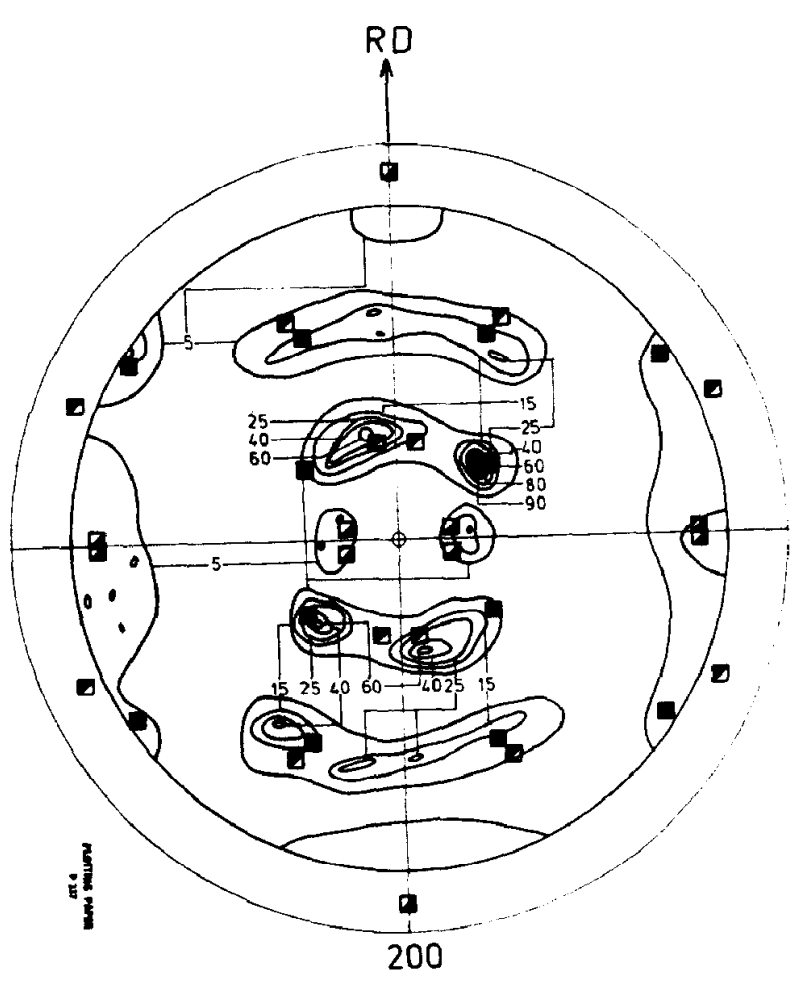

Fra. 4(b). $\{200\}$ pole figure of Ag specimen, rolled 99.5 per cent annealed 30 sec at $140^{\circ} \mathrm{C}$.

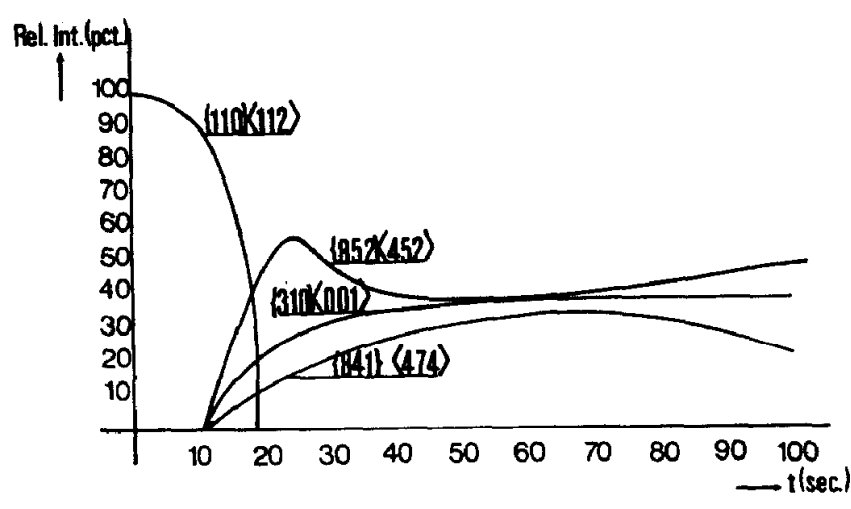

Fig. 5. Qualitative recrystallisation development curves. Rel. intensity of one of texture components $A$ is $Q a / \Sigma Q$.

heat-treatments of $10 \mathrm{sec}$ at $140^{\circ} \mathrm{C}, 30$ and $60 \mathrm{sec}$ at $120^{\circ} \mathrm{C}$ and $180 \mathrm{sec}$ at $100^{\circ} \mathrm{C}$. From these observations it may be concluded that the recrystallisation process starts with an in situ recrystallisation. After a rearrangement of the dislocations in a more or less ordered structure (Fig. 6-10 sec $140^{\circ} \mathrm{C}$ ) isolated fully recrystallised nuclei are observed. In every case recrystallisation twinning was observed (compare Fig. $9-35 \mathrm{sec} 140^{\circ} \mathrm{C}$ ). Shortly after this, isolated grains with a different orientation are appearing in the still heavily deformed parts of the matrix (Fig. 7-180 sec at $\left.100^{\circ} \mathrm{C}\right)$. The orientation of the recrystallised grain $A$ and its immediate surrounding can be seen from the diffraction patterns in Fig. 8. The orientation of $A$ turns out to be (100)[001] while the surrounding matrix has the $(011)[\overline{2} 1 \overline{1}]+(011)[\overline{21} 1]$ twin orientation. These orientations are frequently observed near the first recrystallised grains. Unfortunately it is not possible to obtain a good bright field image of the boundaries between these texture components. This is due to the fact that the viewing plane

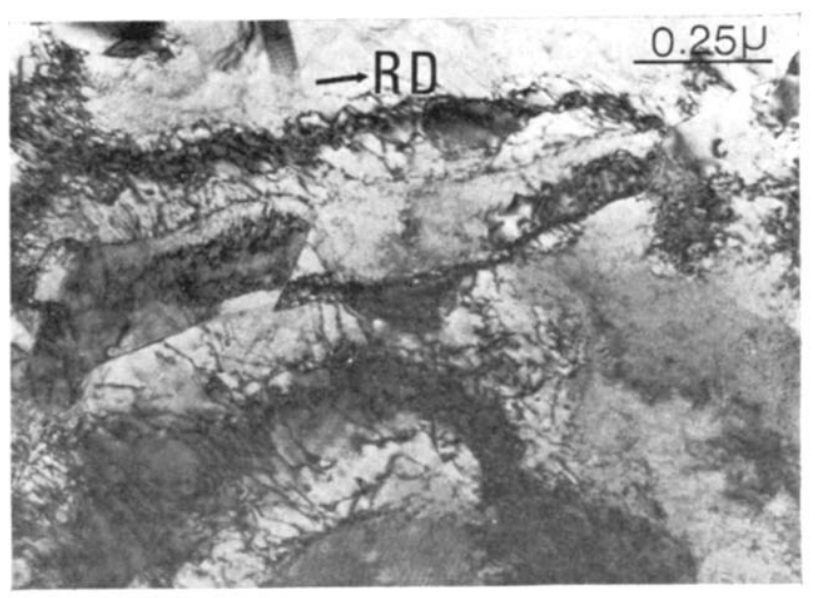

FrG. 6. Bright field image of a Ag specimen rolled 99.5 per cent and heat treated at 10 sec $140^{\circ} \mathrm{C}$. 


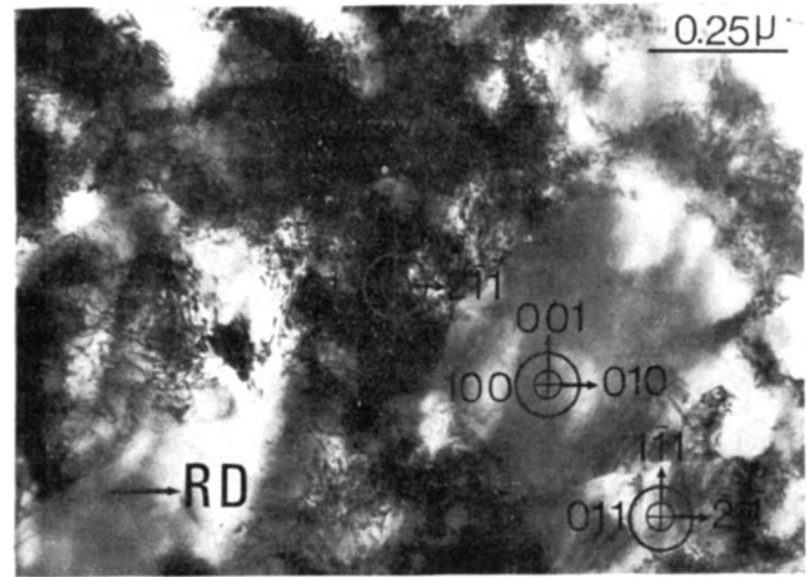

FIG. 7. Bright field image of a $\mathrm{Ag}$ specimen rolled 99.5 per cent and heat treated 180 sec at $100^{\circ} \mathrm{C}$.

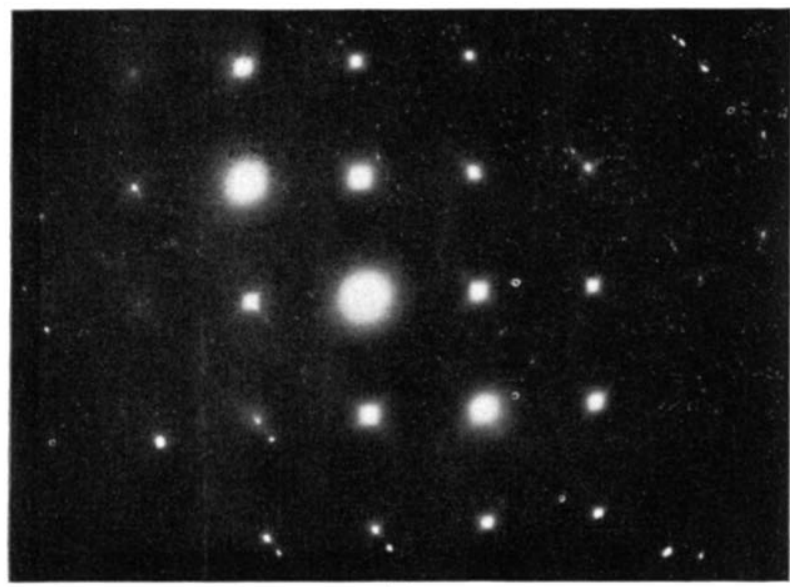

(a)

FIG, 8. Diffraction pattern of the areas indicated in Fig. 7.

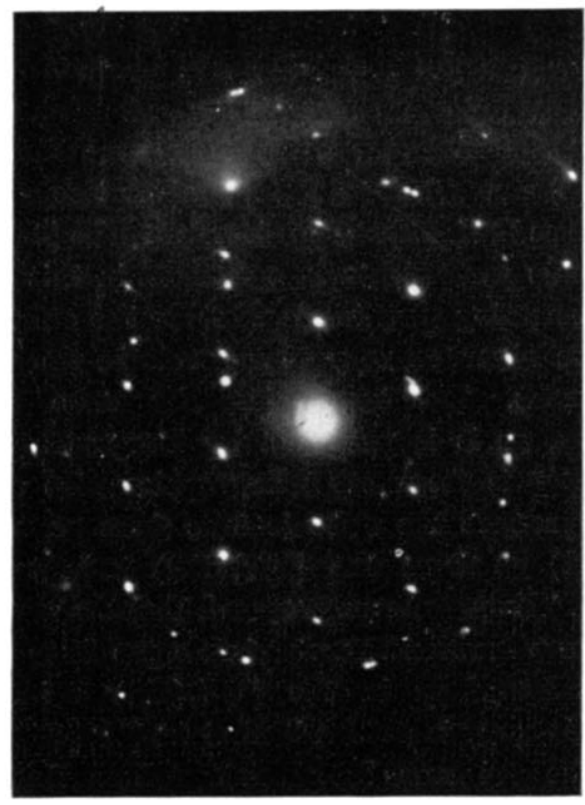

FIG. 8(b).

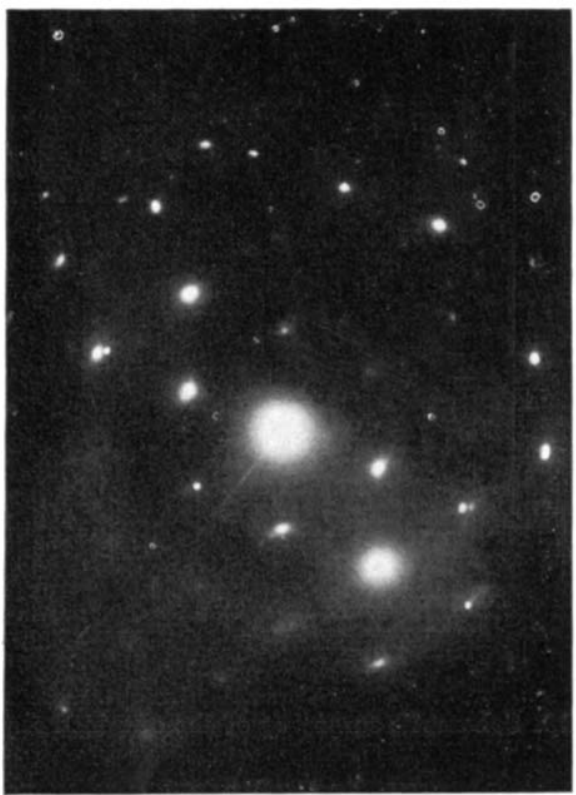

FIG. 8(c).

was the rolling plane, which is "clouded" by the numerous dislocations. It would be advantageous to study a plane which is perpendicular to the transversal direction. In those specimens which are com. pletely or almost completely recrystallised it is noticed once again that the majority of the grains have a twin structure. The orientations which are observed are those mentioned in the previous part as they are measured with the texture goniometer. (Fig. 9$35 \mathrm{sec}$ at $140^{\circ} \mathrm{C}$ ). There is some spread around these orientations, but the number of electron microscopical orientations is insufficient for analytical treatment. The results obtained thus far are summarised schematically in Fig. 10.

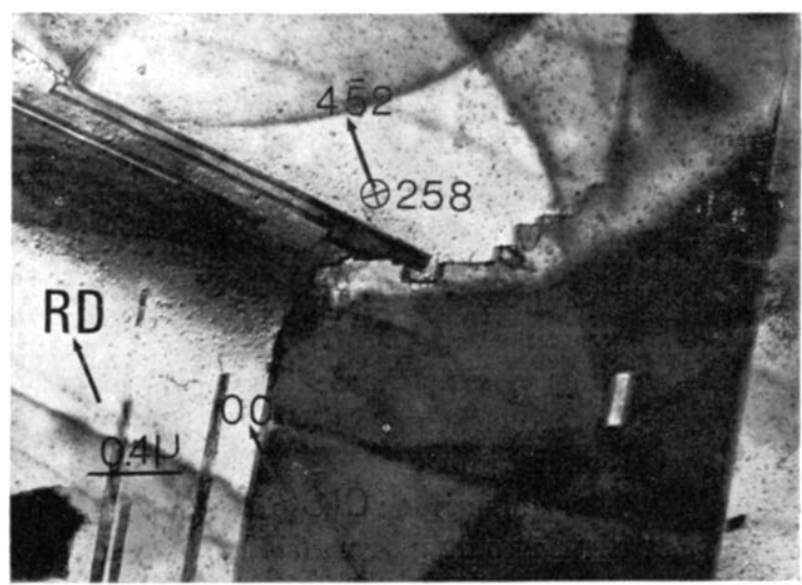

Fra. 9. Bright field image of a Ag specimen rolled 99.5 per cent and annealed $55 \mathrm{sec}$ at $140^{\circ} \mathrm{C}$. 


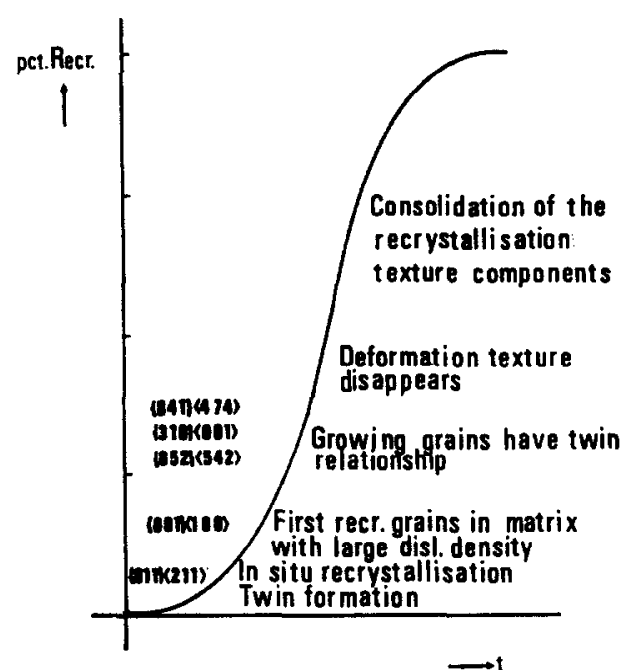

Fra. 10. Schematic summary of the obtained results.

\section{DISGUSSION}

Any theory explaining the texture development due to recrystallisation should explain the observations shown in Fig. 10. The first question is whether the theory of oriented growth can explain this texture development. The type of texture predicted by this theory can be related to the deformation textures which is a $(011)[\overline{21} 1]+(011)[\overline{21} 1]$ texture, by a rotation of $38^{\circ}$ around the plane normals of the active slip planes (111) and (111) (see Fig. 11). A clock wise rotation of the rolling plane normal around (111) will produce a new plane parallel to the rolling plane with

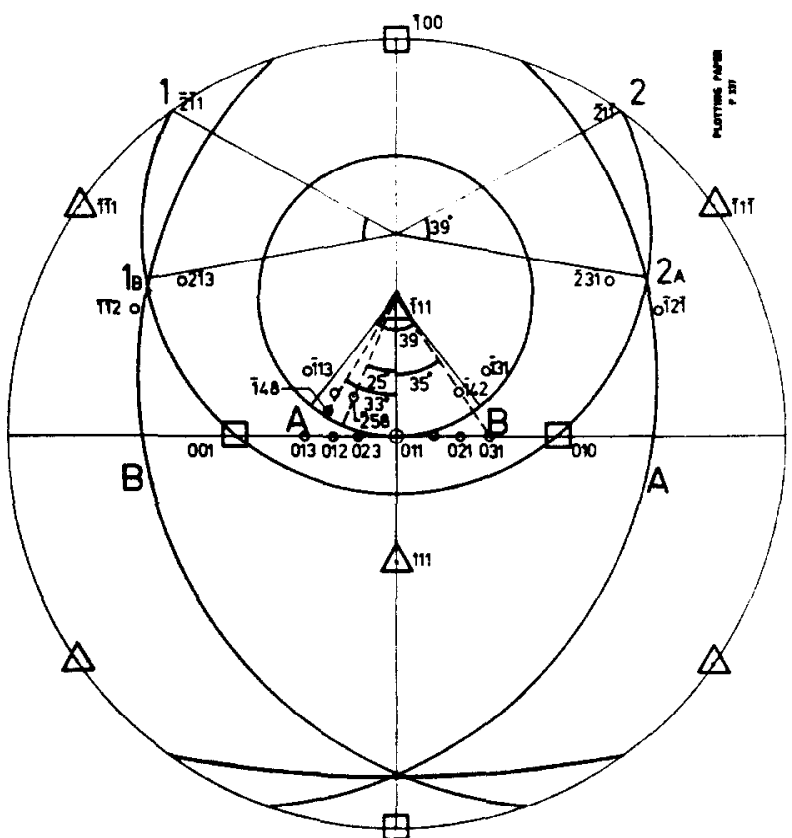

FiG. 11. (011) standard stereographic projection with rotational relationship of the deformation texture and the recrystallisation texture around the (111) axis. an orientation of approximately $(\mathrm{I}, 5,11)(A)$. A counter clock-wise rotation produces a similar $(\overline{1}, 11,5)(B)$ orientation. The great circles of these orientations on which the rotated rolling directions have to be situated are marked $A$ and $B$ in Fig. 11 . A clock-wise rotation of the rolling direction [21I](2) produces a new direction very close to [I2I] $(2 A$, angular distance $4^{\circ}$ ). A counter clock-wise rotation of the alternative rolling direction (1): [2I1] produces a similar [112] direction $(1 B)$. In this way the rotational relationship produces a $(\overline{\mathrm{I}}, 5,11)[\mathrm{T} 2 \mathrm{I}]+(\overline{\mathrm{I}}, 11,5)[\mathrm{IT} 2]$ texture from $(011)[\overline{2} 1 \overline{1}]+(011)[211]$. These "rotation textures" could explain the four $\{841\}\langle 447\rangle$ texture components, but not the other components which are observed.
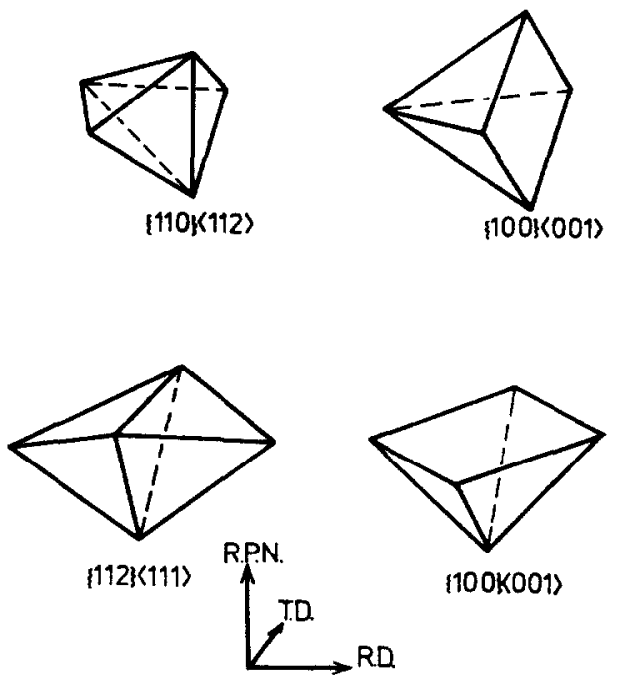

Fig. 12. The inverse Rowland transformation (after C. A. Verbraak).

For the $(031)[100]+(013)[\overline{100}]$ components, the rolling plane normal (013) could be explained, because it is only $7^{\circ} 38^{\prime}$ from $(1,5,11)$ but the rotation of $38^{\circ}$ of $[\overline{211}](1)$ clockwise and [ 211$]$ counter clock-wise do not produce the $[100]$ rolling direction. The $\{852\}\langle 452\rangle$ components can neither be explained in this way.

An interesting question is whether the cube nuclei that were observed may play a role in the texture development. The mechanism for cube texture formation, as it is proposed by Burgers and Verbraak, (12-14) is from crystallographic point of view able to produce the cube texture from as well the $\{112\}\langle 111\rangle$ as from the $\{110\}\langle 112\rangle$ twin textures. (Fig. 12). These authors proposed that the energy for this inverse Rowland mechanism came from the in. coherent boundary in the $\{112\}\langle 111\rangle$ twin. This source of energy is not available in a $\{110\}\langle 112\rangle$ twin texture, so an inverse Rowland transformation would not be possible in this texture. Nevertheless Horinchi 


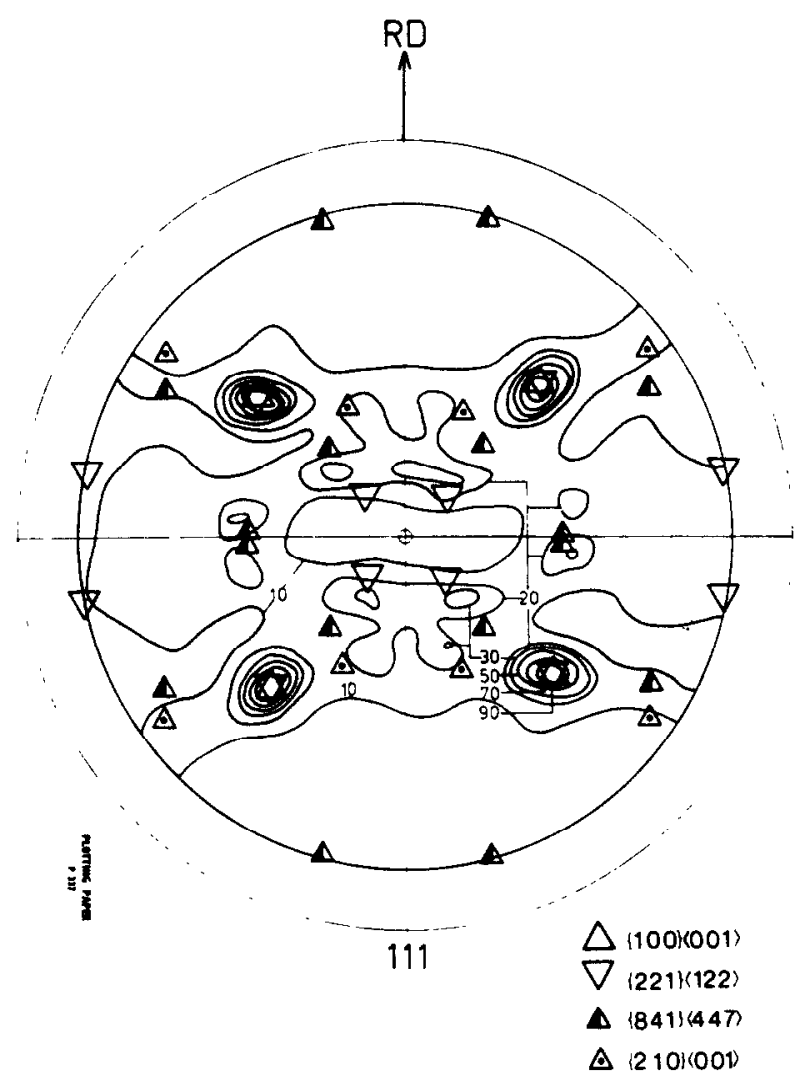

Fig. 13. $\{111\}$ pole figure of a $\mathrm{Ni} 44 \%$ Co alloy, rolled 98 per cent and annealed at $600^{\circ} \mathrm{C}$ during 1800 sec.

et al..$^{(9)}$ and Hinkel et al. ${ }^{(10)}$ observed cube grains in $\mathrm{Cu}$ in a $\{110\}\langle 112\rangle$ oriented matrix. The cube texture will, however, not be able to grow into the $\{110\}\langle 112\rangle$ texture due to the infavorable rotational relationship. According to Verbraak, ${ }^{(10)}$ the inverse Rowland transformation does not only produce the $\{100\}\langle 001\rangle$ texture, but also its twin $\{221\}\langle 112\rangle$ which is supposed to provide an extra accommodation between the cube nucleus and the surrounding matrix. It is known from the investigations of Gindraux and Form, ${ }^{(19)}$ from Peters and Reid ${ }^{(17,18)}$ and from the results presented here, that primary recrystallisation is characterised by twinning. These observations are also supported by the growth accident theory for twin formation by Gleiter (21) which makes continual twinning inevitable during primary recrystallisation. The attention is now drawn at the fact that the twin of the $\{122\}\langle 221\rangle$ texture (the secondary twin of the cube texture) has the orientation $\{841\}\langle 474\rangle$ which has a $34^{\circ}$ rotational relationship with respect to the deformation texture and which is actually observed upon recrystallisation. Theoretically besides the $\{100\}\langle 001\rangle$ $+\{122\}\langle 221\rangle$ textures, the inverse Rowland transformation also has to produce the so called "tilted cube texture." In a $\{112\}\langle 111\rangle$ matrix this is the $\{210\}\langle 001\rangle$ orientation and in a $\{110\}\langle 112\rangle$ texture this is the $\{210\}\langle 120\rangle$ orientation. The $\{210\}\langle 120\rangle$ orientation is never observed to grow into a $\{110\}\langle 112\rangle$ oriented structure, nor is its twin $\{210\}\langle 452\rangle$ (also produced by the inverse Rowland transformation); although these orientations could be responsible for the observed spread in the Ag recrystallisation texture. The twin of $\{210\}\langle 245\rangle$ (the secondary twin of $\{210\}\langle 120\rangle)$ has the orientation $\{852\}\langle 452\rangle$ which fits the observed texture rather well (Figs. 3,4), although its rotational relationship is only $\mathbf{2 5 ^ { \circ }}$. The ternary twin of the tilted cube texture in $\{110\}, 112\rangle$ has an orientation of almost $\{310\}\langle 001\rangle$ which has a rota. tional relationship of $35^{\circ}$ opposite to the secondary twin. Thus, the asymmetrical rotation, mentioned before, which was observed is explained as well. The mechanism proposed here, thus, explains all the observed orientations as well as their twin relationship. It is very interesting to notice that the recrystallisation texture of heavily rolled Ni44Co is composed of $\{100\}\langle 001\rangle+\{841\}\langle 447\rangle+\{210\}\langle 001: \div\{221\}\langle 122\}$ (Fig. 13). From this observation it may be concluded that the mechanism which is proposed above holds for all f.c.c. metals, regardless of their S.F.E. The change

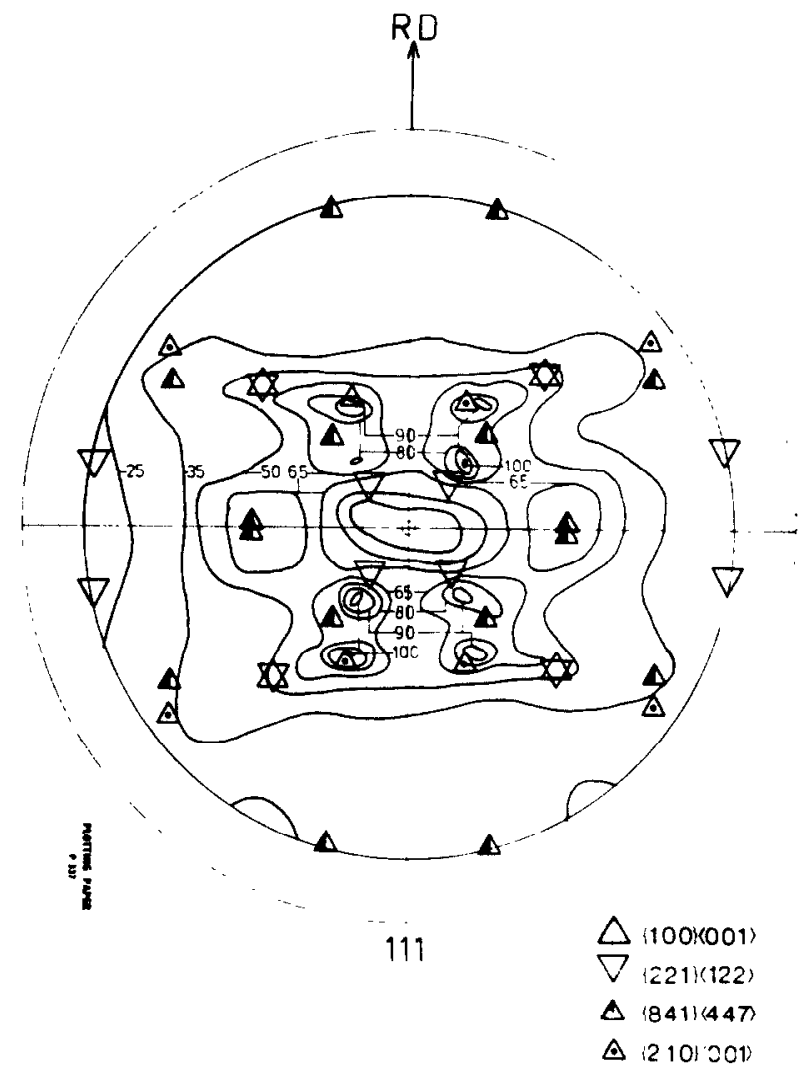

Fra. 14. $\{111\}$ pole figure of a Ni $50 \%$ Co alloy, rolled 98 per cent and annealed at $600^{\circ} \mathrm{C}$ during 1800 sec. 
in S.F.E. makes the deformation texture change. When the S.F.E. is lowered, the amount of Ag type texture increases gradually as F. Haessner showed for a series of Ni-Co alloys ${ }^{(20)}$ (S.F.E. decreases with an increase of Co-content). It is observed that in the recrystallisation textures of $\mathrm{Ni}-\mathrm{Co}$ alloys the $\{841\}\langle 474\rangle$ component increases with the Co-content. This is expected because this type of texture is oriented more favorably for growth in the $\{110\}\langle 112\rangle$ matrix than the cube texture and its twins. Furthermore it is observed that the $\{210\}\langle 001\rangle$ texture which is produced by the inverse Rowland transformation itself in a $\{112\}\langle 111\rangle$ matrix (the tilted cube texture) rotates gradually to $\{310\}\langle 001\rangle$ which is very near to the ternary twin in the tilted cube texture in the $\{110\}\langle 112\rangle$ matrix. It is also striking to notice that the $\{221\}\langle 122\rangle$ texture is eliminated as soon as the $\{841\}\langle 474\rangle$ texture is produced. (Compare the pole figures of recrystallised Ni44Co and Ni50Co Figs. 13,14 .) An important question, however, still remains to be solved: where does the energy for the inverse Rowland mechanism in the $\{110\}\langle 112\rangle$ matrix come from? A possible explanation could be based on the micro-twins observed in the rolled Ag specimens. A considerable part of the energy in these twins is represented by the incoherent tip of kink energy. This may be a driving force for the annihilation of the twins by the inverse Rowland transformation. This might explain too why Verbraak did not observe cube texture formation in Ag single crystals, which were observed to have a rather coarse twinned structure after deformation (14). In this coarse structure the balance between the coherent boundary energy and the incoherent kink energy dips to the first side.

\section{CONCLUSIONS}

From the present results and a number of theoretical considerations the following process for recrvstallisation texture formation is proposed

(1) During the rolling process (in very pure metals) or shortly thereafter in the first stadium of recrystallisation (less pure metals) micro-recrystallisation twins are created.

(2) The coarse twins will grow on further annealling and are retained after completion of the recrystallisation process.

(3) The small twins are annihilated by an inverse Rowland transformation which causes the following texture transitions:

(a) $\{112\}\langle 111\rangle$ (twin) $\rightarrow\{100\}\langle 001\rangle+\{122\}\langle 22]$ $+\{210\}\langle 001\rangle+$ twins

(b) $\{110\}\langle 112\rangle$ (twin) $\rightarrow\{100\}\langle 001\rangle+\{122\}\langle 221\rangle$ $+\{210\}\langle 120\rangle+$ twins.

(4) In case 3(a) all components except the twins of the tilted cube texture are able to grow, so they will make up the recrystallisation texture.

(5) In case 3 (b) due to growth accidents the following twinning occurs:

$\{221\}\langle 122\rangle \rightarrow\{841\}\langle 474\rangle$

$\{210\}\langle 245\rangle$ (twin of the tilted cube texture) $\rightarrow$ $\{\mathbf{8 5 2}\}\langle\mathbf{2 4 5}\rangle \rightarrow\{\mathbf{3 1 0}\}\langle\mathbf{0 0 1}\rangle$.

These twins will grow and they will thus produce the recrystallisation texture.

\section{ACKNOWLEDGEMENTS}

The author wishes to express his deep appreciations to Prof. Dr. Ir. C. A. Verbraak, the originator of this work, for his encouragement and advice. Further grateful thanks are due to Mr. A. M. Nijssen for many helpful discussions in the course of the investigation and to Mr. S. Hoekstra and Mr. H. Groefsema for their experimental aid.

\section{REFERENCES}

1. P. A, BECK and $\mathrm{H}$. $\mathrm{HU}$, in Recrystallisation, Grain growth and Textures, papers presented at a seminar of the A.S.M. (October 16, 17, 1965). A.S.M. Metals Park Ohio (1966).

2. P. A. BECK, Adv. Phys. 3, 245 (1954).

3. P. A. Beck, Acta Met. 1, 230 (1953).

4. $W$. G. Burgers and P. C. Louwerse, Z. Phys, 61, 605 (1931).

5. W. G. Burgers and T. J. Tiedema, Proc. Kon. Ned. Akad. v. Wet.53, 1525 (1950).

6. W. G. Burates, Recr. and Arain Growth in Solid Metals, IXth Solvay Annual Conf. (1951).

7. M. N. Parthasarati and P. A. Beck, Trans. AIME 212 , $875(1958)$

8. B. Liebmani, K. Lücke and G. Masing, Z. Metallk, 47, $57(1956)$.

9. S. Horuichi, T. Okubo and I. Gokyo, Trans. Jap. Inst. Met. 7, 257 (1966).

10. H. Hinkel, G. HaAse and F. Granzer, Acta Met. 15. $1875(1967)$

11. R. K. RAY, W. B. Hurchinson, F. M. C. Besag and R. E. Smallian, J. Microscopy 82,217 (1973).

12. W. G. Burgers and C. A. Verbraak, Acta Met. 5,765 (1957).

13. C. A. Verbratk, Acta Met. 6, 580 (1958)

14. C. A. VerbraAk, Thesis, Delft (1959).

15. II. L. Kronberg and F. M. Wuson, Trans. AIME 185 , $501(1949)$.

16. C. A. VerbraAk, Acta Met. 8, 65 (1960).

17. B. F. Peters, Met. Trans. 4, 757 (1973).

18. B. F. Peters and D. C. REID, Met. Trans. 4, 2851 (1973).

19. G. GrindratX and W. Form, J. Inst. Metals 101, 85 (1973).

20. F. Haessner, $Z$. Metallk. 53, 403 (1962).

21. H. Gleiter, Acta Met. 17, 1421 (1969). 